\title{
Propionate represses the $d n a A$ gene via the methylcitrate pathway-regulating transcription factor, PrpR, in Mycobacterium tuberculosis
}

\author{
Paweł Masiewicz • Marcin Wolański • \\ Anna Brzostek · Jarosław Dziadek • \\ Jolanta Zakrzewska-Czerwińska
}

Received: 11 January 2014/ Accepted: 10 March 2014/Published online: 5 April 2014

(C) The Author(s) 2014. This article is published with open access at Springerlink.com

\begin{abstract}
During infection of macrophages, Mycobacterium tuberculosis, the pathogen that causes tuberculosis, utilizes fatty acids as a major carbon source. However, little is known about the coordination of the central carbon metabolism of M. tuberculosis with its chromosomal replication, particularly during infection. A recently characterized transcription factor called $\operatorname{PrpR}$ is known to directly regulate the genes involved in fatty acid catabolism by $M$. tuberculosis. Here, we report for the first time that PrpR also regulates the dnaA gene, which encodes the DnaA initiator protein responsible for initiating chromosomal replication. Using cell-free systems and intact cells, we demonstrated an interaction between PrpR and the dnaA promoter region. Moreover, real-
\end{abstract}

P. Masiewicz · J. Zakrzewska-Czerwińska ( $\square)$ Department of Microbiology, Ludwik Hirszfeld Institute of Immunology and Experimental Therapy, Polish Academy of Sciences, Wrocław, Poland e-mail: jolanta.zakrzewska@uni.wroc.pl

P. Masiewicz

Structural and Computational Biology Unit, European Molecular Biology Laboratory, Heidelberg, Germany

M. Wolański · J. Zakrzewska-Czerwińska Department of Molecular Microbiology, Faculty of Biotechnology, University of Wrocław, Wrocław, Poland

A. Brzostek · J. Dziadek

Laboratory of Mycobacterium Genetics and Physiology, Institute of Medical Biology, Polish Academy of

Sciences, Łódź, Poland time quantitative reverse-transcription PCR analysis revealed that PrpR acts as a transcriptional repressor of $d n a A$ when propionate (a product of odd-chain-length fatty acid catabolism) was used as the sole carbon source. We hypothesize that PrpR may be an important element of the complex regulatory system(s) required for tubercle bacilli to survive within macrophages, presumably coordinating the catabolism of host-derived fatty acids with chromosomal replication.

Keywords PrpR $\cdot$ dnaA expression ·

Propionate $\cdot$ Fatty acids $\cdot$ Tubercle bacillus

\section{Introduction}

Faithful transmission of genetic material to daughter cells requires the precise regulation of chromosomal replication and its coordination with the cell cycle. Chromosomal replication in all three domains of life is mainly regulated at the initiation step. In bacteria, it is initiated through cooperative binding of the initiator protein, DnaA, to multiple DnaA boxes (9-mers) within the oriC region, which leads to the unwinding of DNA (reviewed in Kaguni 2006; Leonard and Grimwade 2011; Ozaki and Katayama 2009). The activity and availability of both key elements of replication initiation, DnaA and oriC, are tightly 
regulated to ensure that replication is initiated only once per cell cycle. Several factors that regulate replication initiation have been identified in both Gram-negative (Escherichia coli, Caulobacter crescentus) and Gram-positive (Bacillus subtilis, Streptomyces coelicolor) bacteria (Zakrzewska-Czerwińska et al. 2007; Katayama et al. 2010; Wolański et al. 2012). A few regulatory systems, such as the inactivation of DnaA-ATP by ATP hydrolysis, appear to be used universally by all bacteria. In contrast, others systems appear to be specific for particular bacteria, such as the CtrA, GcrA and CcrM proteins, which temporarily and spatially coordinate replication initiation with cell differentiation and cell cycle progression in C. crescentus (Collier 2012).

Surprisingly, little is known about the regulation of DNA replication in response to various environmental conditions and factors (Wang and Levin 2009). Recent studies have demonstrated that there is a direct link between central carbon metabolism (CCM) and the initiation and elongation stages of DNA replication in E. coli (Maciagg et al. 2011, 2012) and B. subtilis (Jannière et al. 2007). These discoveries indicate the existence of a global correlation between metabolic status and the key cell cycle processes leading to bacterial proliferation (e.g., replication). In this light, it is important to investigate the relationship between CCM and replication in intracellular pathogens such as Mycobacterium tuberculosis that utilize compounds "scavenged" from the host.

The success of $M$. tuberculosis as the causative agent of TB lies mostly in its ability to maintain a dormant, non-replicating state for extended periods under unfavorable conditions (reviewed in Gengenbacher and Kaufmann 2012). During the infection of macrophages, M. tuberculosis is exposed to nutrient limitation and thus must re-route its carbon metabolism from sugars to fatty acids and cholesterol (see McKinney et al. 2000; Munoz-Elias and McKinney 2006; Shi et al. 2010). The CCM of $M$. tuberculosis is known to be a key determinant of its pathogenicity (Rhee et al. 2011), but little is known about the coordination of CCM with replication during the transition to dormancy.

In the present work, we show for the first time that PrpR, a transcription factor that regulates genes encoding enzymes responsible for fatty acid catabolism (Masiewicz et al. 2012), represses $d n a A$ expression during M. tuberculosis growth on propionate as a sole carbon source.

\section{Materials and methods}

DNA manipulations, bacterial strains, culture conditions, and protein purification

DNA manipulations were carried out using standard protocols (Sambrook et al. 1989). Enzymes were supplied by Fermentas and Promega; $\left[\gamma^{32} \mathrm{P}\right]$ ATP radioisotope was purchased from Hartmann Analytic; and oligonucleotides were synthesized by Genomed (Poland). The utilized bacterial strains and oligonucleotides, as well as their relevant characteristics, are given in Table 1. M. tuberculosis strain $\mathrm{H} 37 \mathrm{Rv}$ and its derivatives were cultured aerobically at $37{ }^{\circ} \mathrm{C}$ in Middlebrook 7H9 broth (Difco, Detroit, MI.) or on $7 \mathrm{H} 10$ agar plates supplemented with $10 \%$ OADC (oleic acid-albumindextrose-catalase) and $25 \mu \mathrm{g} / \mathrm{ml}$ kanamycin (when required). For RNA extraction and gene expression measurements, $M$. tuberculosis strains were cultivated at $37{ }^{\circ} \mathrm{C}$ either in $7 \mathrm{H} 9+$ OADC medium or in M9 minimal salts medium (Sambrook et al. 1989), containing $2 \mathrm{mM}$ $\mathrm{MgSO}_{4}$ and $0.1 \mathrm{mMCaCl}_{2}$, with glucose, sodium acetate or sodium propionate ( $0.5 \%$ each) as a sole carbon source. The fusion protein, $6 \mathrm{HisPrpR}$, was purified using affinity chromatography (HIS-Select HF resin), as described previously by Masiewicz et al. (2012).

\section{Affinity chromatography}

The intergenic rpmH-dnaA DNA fragment (645 bp) and the oriC region (557 bp) were PCR amplified using M. tuberculosis strain $\mathrm{H} 37 \mathrm{Rv}$ chromosomal DNA as a template and two primer pairs: the MtrpmH_Fw primer plus the 5'-biotin-labeled reverse primer, MtrpmH_Rv; and the MtoriC_Fw primer plus the 5'-biotin-labeled MtoriC_Rv primer (Table 1). The resulting biotinylated DNA fragments $(10 \mathrm{pmol})$ were immobilized on Streptavidin Magnetic Dynabeads (Dynabeads ${ }^{\circledR}$ M-280 Streptavidin, Invitrogen). For experiments, $M$. tuberculosis cultures were grown on $7 \mathrm{H} 9+$ OADC broth to an $\mathrm{OD}_{600}$ of $0.7-0.9$. The cells were harvested by centrifugation and resuspended in chilled phosphate buffered saline (PBS; $0.8 \% \mathrm{NaCl}, 0.02 \% \mathrm{KCl}, 0.144 \% \mathrm{Na}_{2} \mathrm{HPO}_{4}$ and $\left.0.024 \% \mathrm{KH}_{2} \mathrm{PO}_{4}\right)$ supplemented with $1 \mathrm{mM}$ EDTA and protease inhibitors (Complete Protease Inhibitor Cocktail Tablets, Roche). The cells were disrupted in the presence of silica beads (BioSpec Products) using a Mini-BeadBeater-8 (BioSpec Products) for $1 \mathrm{~min}$. 
Table 1 Bacterial strains and oligonucleotides (primers)

\begin{tabular}{|c|c|c|c|}
\hline \multicolumn{4}{|l|}{ Bacterial strains } \\
\hline Strain & \multicolumn{2}{|l|}{ Genotype } & Source \\
\hline M. tuberculosis $\mathrm{H} 37 \mathrm{Rv}$ & \multicolumn{2}{|l|}{ Laboratory strain (Cole et al. 1998) } & $\begin{array}{l}\text { Laboratory } \\
\text { stock }\end{array}$ \\
\hline M. tuberculosis $\Delta$ prpR & \multicolumn{2}{|c|}{ M. tuberculosis $\mathrm{H} 37 \mathrm{Rv}$ with deleted prpR gene (unmarked deletion) } & $\begin{array}{l}\text { Masiewicz } \\
\text { et al. (2012) }\end{array}$ \\
\hline $\begin{array}{l}\text { M. tuberculosis } \\
\quad \Delta p r p R+\text { pMVprpR }\end{array}$ & \multicolumn{2}{|c|}{$\begin{array}{l}\text { M. tuberculosis } \Delta p r p R \text {-complemented strain containing a pMV306-integrated } \\
\text { functional copy of the } p r p R \text { gene under the control of its own promoter }\end{array}$} & $\begin{array}{l}\text { Masiewicz } \\
\text { et al. (2012) }\end{array}$ \\
\hline \multicolumn{4}{|c|}{ Oligonucleotides (primers) } \\
\hline Oligonucleotide & Sequence $\left(5^{\prime}-3^{\prime}\right)$ & \multicolumn{2}{|l|}{ Application } \\
\hline MtrpmH_Fw & GGTCCTTTTGCCCTTGGTCAC & \multirow{4}{*}{\multicolumn{2}{|c|}{ Affinity chromatography }} \\
\hline biotMtrpmH_Rv & biot-TGAACCGGGGTCATCGGTCAA & & \\
\hline MtoriC_Fw & CGGGATCCCACGGCGTGTTCTTCCGACAACG & & \\
\hline biotMtoriC_Rv & biot-CTCTTGTCGTAGCCGCGTCCAT & & \\
\hline pmtdnaA_Fw2 & CCGTTTCAGCGTGGAAACGG & \multirow{2}{*}{\multicolumn{2}{|c|}{$\begin{array}{l}\text { Amplification of } d n a A \text { promoter region } \\
\text { for EMSA and IP }\end{array}$}} \\
\hline MtrpmH_Rv & TGAACCGGGGTCATCGGTCAA & & \\
\hline p1129_Fw & GACGTCAACCGGATCGGCAGC & \multirow{2}{*}{\multicolumn{2}{|c|}{$\begin{array}{l}\text { Amplification of prpDR promoter region } \\
\text { for EMSA and IP }\end{array}$}} \\
\hline p1129_Rv & GGCACCGGAAAACGTCCTCGA & & \\
\hline pmtrA_Fw & CTTGCGGTCTCTGCCGAGCTC & \multirow{2}{*}{\multicolumn{2}{|c|}{$\begin{array}{l}\text { Amplification of } m t r A \text { promoter region } \\
\text { for EMSA and IP }\end{array}$}} \\
\hline pmtrA_Rv & TGGTGTCCATGGTGTCACCACA & & \\
\hline RT_MtdnaA_Fw & TACACGCGGCAGGCAACT & \multirow{2}{*}{\multicolumn{2}{|c|}{ dnaA $(r v 0001)$ transcription }} \\
\hline RT_MtdnaA_Rv & GGAGACATATTTGACCCGCATT & & \\
\hline RT_1129_Fw & GAGGGATACCGTTCATCTTCGT & \multirow{2}{*}{\multicolumn{2}{|c|}{$\operatorname{prpR}(r v 1129 c)$ transcription }} \\
\hline RT_1129_Rv & GCGGACTGTCGCTTTGAGA & & \\
\hline RT_MtsigA_Fw & GGTGATTTCGTCTGGGATGAA & \multirow{2}{*}{\multicolumn{2}{|c|}{ sigA (rv2703) transcription }} \\
\hline RT_MtsigA_Rv & GCTACCTTGCCGATCTGTTTG & & \\
\hline
\end{tabular}

The samples were then centrifuged $(16,000 \times g$, $15 \mathrm{~min}, 4^{\circ} \mathrm{C}$ ) and the protein concentrations in the supernatants were determined using the Bradford assay (Bradford 1976). For "fishing" experiments, $5 \mathrm{mg}$ of total protein extract (final volume, $1 \mathrm{ml}$ ) was incubated with 10 pmol of DNA-immobilized Dynabeads with constant gentle mixing for $1 \mathrm{~h}$ at $25^{\circ} \mathrm{C}$. The Dynabeads were then washed and eluted with PBS supplemented with increasing $\mathrm{NaCl}$ concentrations. The eluates were resolved by $10 \%$ SDS-PAGE, and the gels were stained with Coomassie brilliant blue. Visible protein band was excised from the gel and analyzed by mass spectrometry.

Whole-cell immunoprecipitation assay

The immunoprecipitation assay was performed as described previously (Jakimowicz et al. 2007;
Masiewicz et al. 2012). Briefly, M. tuberculosis $\mathrm{H} 37 \mathrm{Rv}$ wild type and prpR-deletion strains were cultivated in $7 \mathrm{H} 9+\mathrm{OADC}$ broth at $37{ }^{\circ} \mathrm{C}$ to $\mathrm{OD}_{600}=0.9$ and treated with glutaraldehyde $(1 \%)$ for $5 \mathrm{~min}$, and the cross-linked nucleoprotein complexes were immunoprecipitated with anti-PrpR antibodies, as described previously (Masiewicz et al. 2012). Cells treated in parallel without cross-linking served as negative controls. The immunoprecipitated DNA was PCR amplified using primers flanking the $d n a A$ and $p r p R$ promoter regions. Two independent experiments of immunoprecipitation assays were carried out.

Electrophoretic mobility shift assay (EMSA)

EMSAs were carried out as described previously (Masiewicz et al. 2012). A DNA fragment (100-150 ng) was 
incubated with increasing amounts of purified $6 \mathrm{HisPrpR}$ protein in $1 \times$ binding buffer $(50 \mathrm{mM}$ Tris- $\mathrm{HCl} \mathrm{pH} 7.5$, $50 \mathrm{mM} \mathrm{KCl}, 10 \mathrm{mM} \mathrm{MgCl} 2,10 \%$ glycerol, $0.5 \mathrm{mM}$ EDTA) for $30 \mathrm{~min}$ at $25^{\circ} \mathrm{C}$. The nucleoprotein complexes were resolved on $4 \%$ polyacrylamide gels at approximately $8{ }^{\circ} \mathrm{C}$ in $0.25 \times$ TBE buffer at $5-10 \mathrm{~V} \mathrm{~cm}^{-1}$, and complexes were analyzed with a Typhoon 8600 Variable Mode Imager and the Image Quant software (Molecular Dynamics).

\section{RNA extraction and reverse transcription}

RNA was extracted from $M$. tuberculosis cultures incubated in M9 minimal medium containing various carbon sources. Since this minimal medium does not sustain robust growth of $M$. tuberculosis, bacteria were first precultured in $7 \mathrm{H} 9+\mathrm{OADC}$ broth to an $\mathrm{OD}_{600}$ of 0.6-0.8. Next, cells were washed twice with M9 minimal medium containing acetate, glucose or propionate $(0.5 \%)$, resuspended in the respective minimal medium and incubated at $37{ }^{\circ} \mathrm{C}$ for an additional $48 \mathrm{~h}$. The cultures were then collected by centrifugation $\left(6000 \times g, 10 \mathrm{~min}, 4{ }^{\circ} \mathrm{C}\right)$, and RNA extraction was carried out according to the previously described protocol (Masiewicz et al. 2012). The reverse transcription reactions were carried out using a SuperScript III First-Strand Synthesis SuperMix kit (Invitrogen) and random hexanucleotides, according to the manufacturer's protocol. The reaction products were analyzed by agarose gel electrophoresis.

\section{Quantitative real-time PCR}

SYBR green-based real-time PCR $(2 \times$ HS-PCR Mix SYBR A; A\&A Biotechnology) was used to quantify the mRNA levels of the dnaA gene in M. tuberculosis H37Rv wild type, $\Delta p r p R$, and complemented strains cultivated on media with different carbon sources. To exclude the possibility of secondary structure formation, we used the Primer Express 3.0 (Applied Biosystems) application to design the primers, which are listed in Table 1. Reactions were performed on a StepOne Plus apparatus with the StepOne Software 2.0 (both from Applied Biosystems), according to the manufacturer's instructions. The relative quantity of dnaA mRNA was determined by reference to the mRNA levels of the $M$. tuberculosis housekeeping gene, sigA. Three independent experiments with cDNA templates derived from RNA isolated from three independent $M$. tuberculosis cultures were carried out.

Statistical analysis

Differences between experimental groups were determined by the Student's $t$ test. $P$ values of $<0.05$ were considered significant, and were calculated using the Excel 2007 software (Microsoft Office).

\section{Results and discussion}

PrpR interacts weakly with the dnaA promoter region

To identify dnaA promoter (pdnaA)- and oriC regionbinding protein(s) that might control the initiation of replication in $M$. tuberculosis, we performed streptavidin affinity chromatography using biotinylated DNA fragment (Fig. 1b) containing either the dnaA promoter region (645 bp, Fig. 1a) or the oriC region (557 bp, data not shown) as bait against cell extracts prepared from M. tuberculosis $\mathrm{H} 37 \mathrm{Rv}$ cultured to an $\mathrm{OD}_{600}$ of 0.9 on $7 \mathrm{H} 9+$ OADC medium. We identified a putative $d n a A$ promoter region-binding protein of $\sim 60 \mathrm{kDa}$ (Fig. 1b) but no binding protein was identified for the oriC region (presumably due to the fact that frequently the interactions between proteins and $\mathrm{oriC}$ are transient). The protein was identified by mass spectrometry (47\% protein sequence coverage) as corresponding to $\mathrm{Rv} 1129 \mathrm{c}(\operatorname{PrpR})$, a recently described transcriptional factor that is directly involved in regulating the methylcitrate and glyoxylate pathways (Masiewicz et al. 2012). The PrpR protein was shown to bind the promoter regions of genes encoding the key enzymes of the methylcitrate (methylcitrate dehydratase [PrpD] and methylcitrate synthase [PrpC]) and glyoxylate (isocitrate lyase [Icl1]) cycles. In addition, we recently showed that PrpR interacts specifically with the 8-bp palindromic sequence, TTTGCAAA (Masiewicz et al. 2012). In the present work, using in silico search we identified only one putative PrpR binding sequence in the dnaA promoter; this sequence differs from the high affinity binding sequence by two nucleotides (TTTtCAAc). Interestingly, the identified sequence is located immediately downstream the transcription start site (transcription from the p2dnaA promoter, see Fig. 1a) 




B Dynabeads streptavidin



Fig. 1 Identification of protein(s) binding the rpmH-dnaA intergenic region of $M$. tuberculosis. A Schematic depiction of the $M$. tuberculosis rpmH-dnaA intergenic region. The positions of transcription start sites, p1, p2 (Salazar et al. 2003; Li et al. 2010) and PrpR binding site are indicated by bend arrow and gray square, respectively. Primers MtrpmH_Fwor, pmtdnaA_Fw2, and MtrpmH_Rv were used to amplify a 645-bp intergenic region for affinity chromatography or a 270-bp dnaA promoter fragment for EMSA analysis (Table 1). B Streptavidin affinity chromatography using a biotinylated

(Salazar et al. 2003; Li et al. 2010). To verify that PrpR was able to bind the $d n a A$ promoter region in vitro, we performed an EMSA. This binding was confirmed, although the purified PrpR protein exhibited a lower affinity toward the dnaA promoter region than toward a DNA fragment containing the prefect palindrome (e.g., its own promoter, pprpR) (Fig. 2a). A single nucleoprotein PrpR-pdnaA complex was visible in reactions containing $200 \mathrm{nM}$ protein, whereas incubation with higher protein concentrations $(500,1,000$ $\mathrm{nM}$ ) resulted in the formation of two nucleoprotein complexes probably as a result of PrpR dimer binding (PrpR forms stable dimers and possibly trimers, Masiewicz et al. 2012). It has to be noted that the $m t r A$ promoter region, which served as a negative control, was not bound by the PrpR protein (even at
rpmH-dnaA intergenic region as bait. The PCR amplified rpmH-dnaA region (10 pmol) was immobilized on Dynabeads and incubated with protein extracts $(5 \mathrm{mg})$ prepared from $M$. tuberculosis $\mathrm{H} 37 \mathrm{Rv}$ grown on $7 \mathrm{H} 9+\mathrm{OADC}$ medium $\left(\mathrm{OD}_{600}=0.9\right)$. The Dynabeads were then washed and eluted with PBS buffer supplemented with increasing concentrations of $\mathrm{NaCl}$. The eluted proteins were resolved by $10 \%$ SDS-PAGE, and visible bands were excised for analysis by mass spectrometry

highest concentration). Surface plasmon resonance (SPR) analysis confirmed the weak interaction between PrpR and the dnaA promoter. The dissociation of PrpR from the dnaA promoter was much faster than that from the $p r p R$ promoter region, suggesting that the complexes between PrpR the dnaA promoter are not stable (data not shown).

To determine whether the PrpR regulator binds the dnaA gene promoter region in $M$. tuberculosis, we performed glutaraldehyde cross-linking of proteins to DNA in intact cells, followed by selective immunoprecipitation of the protein-DNA complexes with anti PrpR antibodies, as described previously (Masiewicz et al. 2012). Both PrpR-pdnaA and PrpR-pprpR (positive control) complexes were detected, whereas no signal (or faint background signal) was observed 
A

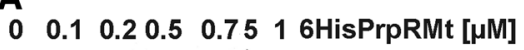

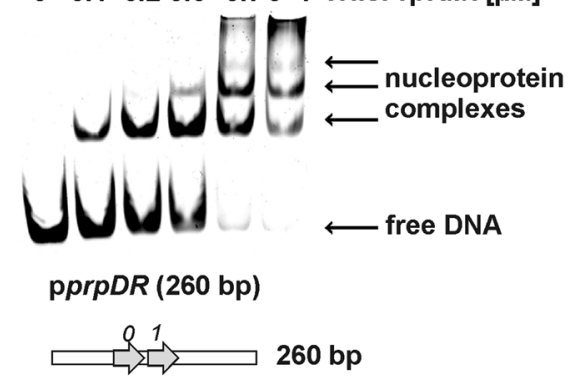

$\begin{array}{lllll}0 & 0.2 & 0.5 & 1 & 6 H i s P r p R M t\end{array}[\mu M]$

$\begin{array}{lllll}0 & 0.2 & 0.5 & 1 & 6 H i s P r p R M t\end{array}[\mu M]$
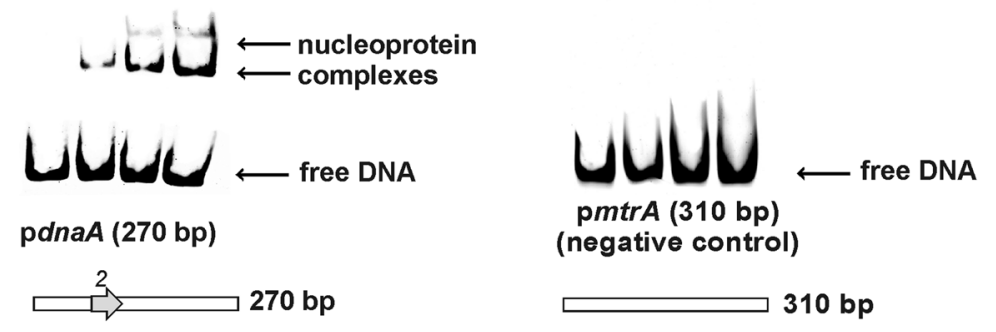

B pprpDR (positive control)
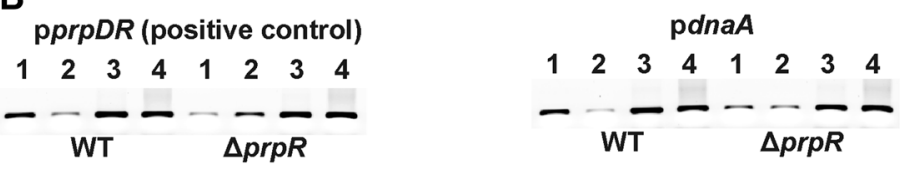

1: cross-link+anti-PrpR 2: anti-PrpR (-)

Fig. 2 PrpR interacts with the dnaA promoter region in vitro and in vivo. A EMSA: a DNA fragment containing the dnaA promoter region (PCR amplified with primers pmtdnaA_Fw2 and MtrpmH_Rv, Table 1) was incubated with a non-specific competitor and increasing amounts of 6HisPrpR, and the nucleoprotein complexes were analyzed on a $4 \%$ polyacrylamide gel; prpDR (containing the perfect PrpR biding site) and the $m t r A$ promoter region served as positive and negative controls, respectively. Arrows along horizontally orientated bars inserted below each figure indicate number of PrpR boxes in corresponding DNA fragment. Digits above arrows indicate number of nucleotide mismatches from the consensus

from a prpR-deletion strain or PrpR-pmtrA, which served as negative controls (Fig. 2b).

Collectively, these results indicate that PrpR binds the $d n a A$ promoter region relatively weakly in vitro and within intact $M$. tuberculosis cells. This suggests that, in addition to the regulation of fatty acid catabolism, PrpR might play a role in regulating the expression of the dnaA gene, which is responsible for the initiation of chromosomal replication.

PrpR represses transcription of $d n a A$

during growth on propionate

We previously demonstrated that the $p r p R$ gene is most highly expressed during the growth of $M$. tuberculosis on propionate, a degradation product of odd-chain-length fatty acids and cholesterol (Masiewicz et al. 2012). The growth of M. tuberculosis on medium containing propioniate as the sole carbon
(TTTGCAAA) within each PrpR box. B In vivo immunoprecipitation: PrpR-DNA complexes cross-linked with glutaraldehyde were immunoprecipitated with anti-6HisPrpR polyclonal antibodies (sample 1). PCR was carried out with the following primer pairs: p1129_Fw and p1129_Rv (pprpDR, positive control); pmtdnaA_Fw2 and MtrpmH_Rv (pdnaA); and pmtrA_Fw and pmtrA_Rv (pmtrA, negative control). A second negative control (2) consisted of extracted DNA subjected to immunoprecipitation without cross-linking. Positives controls $(+)$ were also performed using templates obtained from strains subjected only to cross-linking (3) or total DNA extracted from the cells (4)

source was impaired in contrast to growth on glucose (Masiewicz et al. 2012). Under such conditions, one would expect that the high expression of PrpR might influence the expression of the $d n a A$ gene. To test this hypothesis, we performed qRT-PCR analysis of $d n a A$ expression using RNA isolated from the wild type and prpR-deleted M. tuberculosis strains growing on M9 minimal medium containing glucose, acetate or propionate as a sole source of carbon. In this experiment, we measured the activity of both $\mathrm{p} 1$ and $\mathrm{p} 2 \operatorname{dnaA}$ promoters (using primers complementary to dnaA gene, Table 1). The expression level of dnaA in the $\triangle p r p R$ strain growing on propionate was four-fold higher than that in the wild type strain, suggesting that PrpR may act as a repressor of dnaA gene expression (Fig. 3). Notably, we did not observe any significant difference in $d n a A$ expression when these strains were cultivated on minimal medium containing glucose or acetate (Fig. 3). It must be mentioned that in the $M$. 

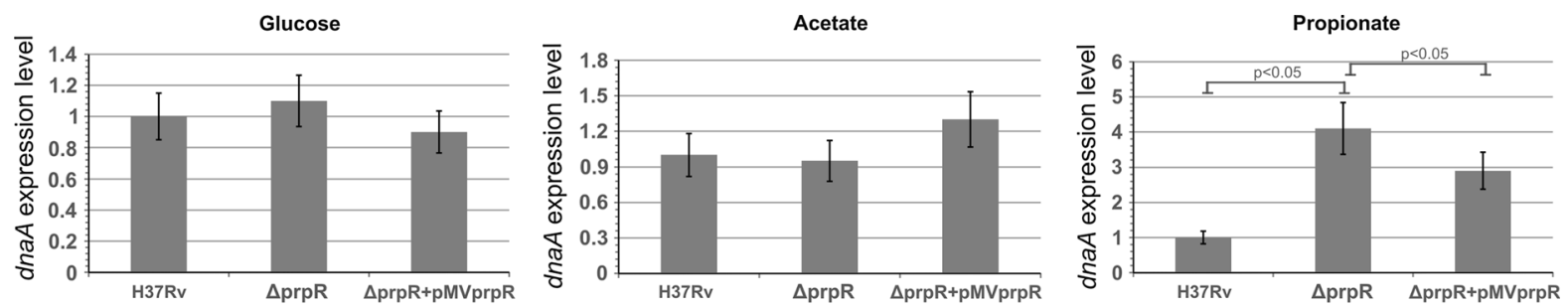

Fig. 3 PrpR represses $d n a A$ gene expression during growth on propionate. Total RNA was extracted from cultures grown in M9 minimal medium containing glucose, acetate or propionate $(0.5 \%)$ as the carbon source. PCR was carried out with primers RT_MtdnaA_Fw and RT_MtdnaA_Rv. The mRNA levels of dnaA were normalized with respect to that of the constitutively

tuberculosis $\triangle p r p R$ complemented strain the repression of $d n a A$ gene on propionate was not completely restored (Fig. 3) (despite the fact that the expression level of $\operatorname{prpR}$ gene was not altered compared to the wild type strain, data not shown). However, the complementing copy of the prpR gene was introduced on the M. tuberculosis chromosome together with its promoter region containing strong (TTTGCAAA) PrpR boxes (in addition to the PrpR binding sites present in the native locus - a common prpD and $p r p R$ promoter region), which presumably titrated PrpR protein away from the dnaA promoter region what could result in higher that in the wild type $d n a A$ expression. It is noteworthy that the expression of prpD gene (activated by $\operatorname{PrpR}$ ) in the M. tuberculosis $\triangle p r p R$ complemented strain did also not reach the level measured in the wild type strain (Masiewicz et al. 2012).

The relatively low affinity of PrpR towards the dnaA promoter is presumably compensated by the elevated level of the protein in M. tuberculosis during growth on propionate. It is worth mentioning that $M$. tuberculosis utilizes fatty acids and cholesterol as a major carbon source in host macrophages during infection (Gengenbacher and Kaufmann 2012; Rhee et al. 2011). Thus, the data presented here and in our earlier study (Masiewicz et al. 2012) suggest that PrpR might play a dual role in media containing fatty acids and cholesterol as the sole carbon source, acting both as an activator of genes involved in fatty acid catabolism including its own gene and as a repressor of the dnaA gene (Fig. 4). It is worth mentioning that besides PrpR there are also DnaA and MtrA proteins that may be directly involved in negative regulation of dnaA gene expression in Mycobacterium by binding expressed housekeeping gene, sigA. Means were calculated from three independent experiments and three determinations per experiment. The error bars indicate standard deviations of triplicate samples. Statistical significance was calculated by the Student's $t$ test

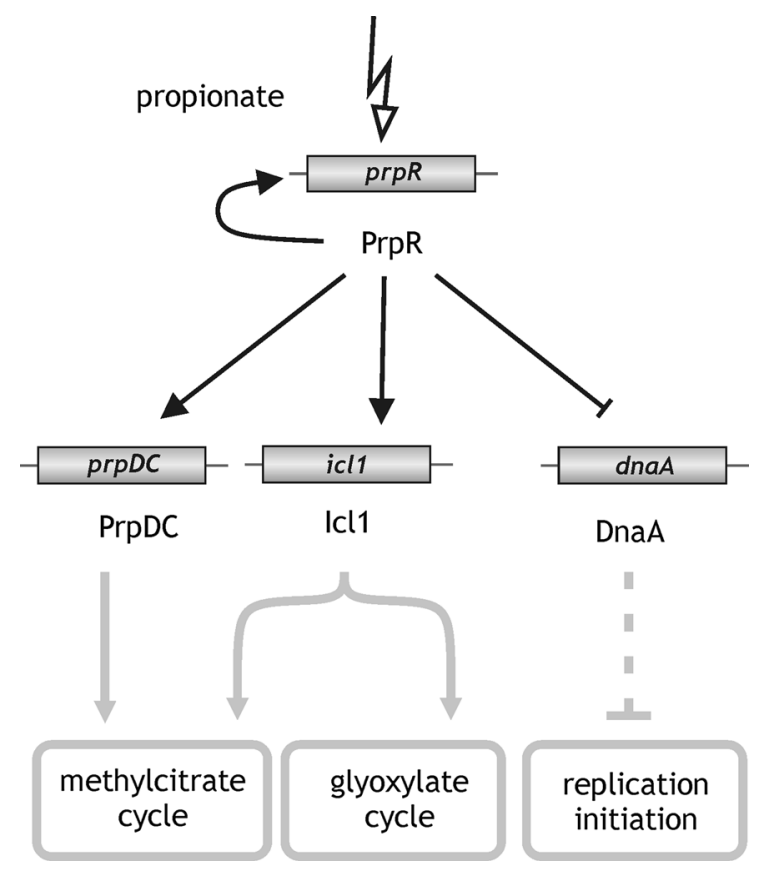

Fig. 4 PrpR coordinates fatty acid catabolism with the initiation of chromosomal replication. In M. tuberculosis, PrpR activates the expression of genes involved in the methylcitrate and glyoxylate cycles, and also inhibits dnaA gene expression. Perpendicular lines indicate negative regulation. Adapted from Masiewicz et al. (2012)

dnaA promoter region (Salazar et al. 2003; Fol et al. 2006; Nguyen et al. 2010). It is noteworthy to point out that the MtrA is supposed also to negatively influence DnaA oligomerization along oriC and thus chromosome replication by binding DnaA boxes within oriC (Rajagoplan et al. 2010).

Tubercle bacilli can survive for decades in humans or hypoxic- and nutrient-depleted media (Hett and Rubin 2008). However, surprisingly little is known 
about the regulatory mechanisms responsible for the ability of these bacilli to enter and exit dormancy. Based on the novel findings presented herein and on our earlier study (Masiewicz et al. 2012) we hypothesize that PrpR could be an important element of the complex regulatory system(s) required for the persistence of TB within macrophages, controlling both the catabolism of host-derived fatty acids and the initiation of chromosomal replication (Fig. 4).

Acknowledgments This work was supported by the WCB EIT + (POIG 1.1. EIT+, Project 3.1.BioMed), and JZC and PM gratefully acknowledge financial support received from the Foundation for Polish Science (MISTRZ Programme).

Addendum Some of our present results were presented as posters during the EMBO workshop "Frontiers of Prokaryotic Cell Biology" held on August 24-27, 2009, in Oxford, UK ("Searching for novel proteins involved in regulation of chromosome replication in Mycobacterium") and the EMBO conference "Replication/repair and segregation of chromosomes" held on June 13-17, 2010, in Freiburg (Germany) ("Characterization of a novel Mycobacterium tuberculosis transcription factor regulating genes involved in replication and carbon metabolism").

Open Access This article is distributed under the terms of the Creative Commons Attribution License which permits any use, distribution, and reproduction in any medium, provided the original author(s) and the source are credited.

\section{References}

Bradford MM (1976) A rapid and sensitive method for the quantitation of microgram quantities of protein utilizing the principle of protein-dye binding. Anal Biochem 72:248-254

Cole ST, Brosch R, Parkhill J, Garnier T, Churcher C, Harris D, Gordon SV, Eiglmeier K, Gas S, Barry CE III et al (1998) Deciphering the biology of Mycobacterium tuberculosis from the complete genome sequence. Nature 393:537-544

Collier J (2012) Regulation of chromosomal replication in Caulobacter crescentus. Plasmid 67:76-87

Fol M, Chauhan A, Nair NK, Maloney E, Moomey M, Jagannath C, Madiraju MV, Rajagoplan M (2006) Modulation of Mycobacterium tuberculosis proliferation by MtrA, an essential two-component response regulator. Mol Microbiol 60:643-657

Gengenbacher M, Kaufmann SH (2012) Mycobacterium tuberculosis: success through dormancy. FEMS Microbiol Rev 36:514-532

Hett EC, Rubin EJ (2008) Bacterial growth and cell division: a mycobacterial perspective. Microbiol Mol Biol Rev 72:126-156
Jakimowicz D, Brzostek A, Rumijowska-Galewicz A, Zydek P, Dolzblasz A, Smulczyk-Krawczyszyn A, Zimniak T, Wojtasz L, Zawilak-Pawlik A, Kois A, Dziadek J, Zakrzewska-Czerwińska J (2007) Characterization of the mycobacterial chromosome segregation protein ParB and identification of its target in Mycobacterium smegmatis. Microbiology 153:4050-4060

Jannière L, Canceill D, Suski C, Kanga S, Dalmais B, Lestini R, Monnier AF, Chapuis J, Bolotin A, Titok M, Le Chatelier E, Ehrlich SD (2007) Genetic evidence for a link between glycolysis and DNA replication. PLoS ONE 16:e447

Kaguni M (2006) DnaA: controlling the initiation of bacterial DNA replication and more. Annu Rev Microbiol 60:351-375

Katayama T, Ozaki S, Keyamura K, Fujimitsu K (2010) Regulation of the replication cycle: conserved and diverse regulatory systems for DnaA and oriC. Nat Rev Microbiol 8:163-170

Leonard AC, Grimwade JE (2011) Regulation of DnaA assembly and activity: taking directions from the genome. Annu Rev Microbiol 65:19-35

Li Y, Zeng J, Zhang H, He ZG (2010) The characterization of conserved binding motifs and potential target genes for $M$. tuberculosis MtrAB reveals a link between the two-component system and the drug resistance of M. smegmatis. BMC Microbiol 10:242

Maciąg M, Nowicki D, Janniere L, Szalewska-Pałasz A, Węgrzyn G (2011) Genetic response to metabolic fluctuations: correlation between central carbon metabolism and DNA replication in Escherichia coli. Microb Cell Fact 31(10): 19

Maciąg M, Nowicki D, Szalewska-Pałasz A, Węgrzyn G (2012) Central carbon metabolism influences fidelity of DNA replication in Escherichia coli. Mutat Res 731:99-106

Masiewicz P, Brzostek A, Wolański M, Dziadek J, ZakrzewskaCzerwińska J (2012) A novel role of the PrpR as a transcription factor involved in the regulation of methylcitrate pathway in Mycobacterium tuberculosis. PLoSOne 7:e43651

McKinney JD, HonerzuBentrup K, Munoz-Elias EJ, Miczak A, Chen B, Chan WT, Swenson D, Sacchettini JC, Jacobs WR Jr, Russell DG (2000) Persistence of Mycobacterium tuberculosis in macrophages and mice requires the glyoxylate shunt enzyme isocitrate lyase. Nature 406:735-738

Munoz-Elias EJ, McKinney JD (2006) Carbon metabolism of intracellular bacteria. Cell Microbiol 8:10-22

Nguyen HT, Wolff KA, Cartabuke RH, Ogwang S, Nguyen L (2010) A lipoprotein modulates activity of the MtrAB twocomponent system to provide intrinsic multidrug resistance, cytokinetic control and cell wall homeostasis in Mycobacterium. Mol Microbiol 76:348-364

Ozaki S, Katayama T (2009) DnaA structure, function, and dynamics in the initiation at the chromosomal origin. Plasmid 62:71-82

Rajagoplan M, Dziedzic R, Al Zayer M, Stankowska D, Ouimet MC, Bastedo DP, Marczynski GT, Madiraju MV (2010) Mycobacterium tuberculosis origin of replication and the promoter for immunodominant secreted antigen $85 \mathrm{~B}$ are the targets of MtrA, the essential response regulator. J Biol Chem 285:15816-15827 
Rhee KY, de Carvalho LP, Bryk R, Ehrt S, Marrero J, Park SW, Schnappinger D, Venugopal A, Nathan C (2011) Central carbon metabolism in Mycobacterium tuberculosis: an unexpected frontier. Trends Microbiol 19:307-314

Salazar L, Guerrero E, Casart Y, Turcios L, Bartoli F (2003) Transcription analysis of the $d n a A$ gene and oriC region of the chromosome of Mycobacterium smegmatis and Mycobacterium bovis BCG, and its regulation by the DnaA protein. Microbiology 149:773-784

Sambrook J, Fritsch EF, Maniatis T (1989) Molecular cloning: a laboratory manual, 2nd edn. Cold Spring Harbor Laboratory Press, New York

Shi L, Sohaskey CD, Pfeiffer C, Datta P, Parks M, McFadden J, North RJ, Gennaro ML (2010) Carbon flux rerouting during Mycobacterium tuberculosis growth arrest. Mol Microbiol 78:1199-1215

Wang JD, Levin PA (2009) Metabolism, cell growth and the bacterial cell cycle. Nat Rev Microbiol 7:822-827

Wolański M, Jakimowicz D, Zakrzewska-Czerwińska J (2012) AdpA, key regulator for morphological differentiation regulates bacterial chromosome replication. Open Biol 2:120097

Zakrzewska-Czerwińska J, Jakimowicz D, Zawilak-Pawlik A, Messer W (2007) Regulation of the initiation of chromosomal replication in bacteria. FEMS Microbiol Rev $31: 378-387$ 